\title{
Asymmetric Adjustments in the Ethanol and Grains Markets*
}

\author{
Chia-Lin Chang \\ National Chung Hsing University \\ Taichung, Taiwan \\ Li-Hsueh Chen \\ California State University-Los Angeles \\ Los Angeles, California

\section{Shawkat Hammoudeh**} \\ Drexel University \\ Philadelphia, PA \\ Michael McAleer \\ Econometric Institute \\ Erasmus School of Economics \\ Erasmus University Rotterdam \\ and \\ Tinbergen Institute \\ The Netherlands \\ and \\ Institute of Economic Research \\ Kyoto University, Japan
}

\section{EI 2010-78}

December 2010

\footnotetext{
* The first author wishes to acknowledge the financial support of the National Science Council, Taiwan. The fourth author is most grateful for the financial support of the Australian Research Council, National Science Council, Taiwan, and the Japan Society for the Promotion of Science. ** Corresponding author. hammousm@drexel.edu
} 


\begin{abstract}
This paper examines the long- and short-run asymmetric adjustments for nine pairs of spot and futures prices, itemized as three own pairs for three different bio-fuel ethanol types, three own pairs for three related agricultural products, namely corn, soybeans and sugar, and three cross pairs that included hybrids of the spot price of each of the agricultural products and an ethanol futures price. Most of the spreads' asymmetric adjustments generally happen during narrowing. The three ethanol pairs that contain the eCBOT futures with each of Chicago spot, New York Harbor spot and Western European (Rotterdam) spot show different longrun adjustments, arbitrage profitable opportunities and price risk hedging capabilities. The asymmetric spread adjustments for the three grains are also different, with corn spread showing the strongest long-run widening adjustment, and sugar showing the weakest narrowing adjustment. Among others, the empirical analysis indicates the importance of potentially hedging the spot prices of agricultural commodities with ethanol futures contracts, which sends an important message that the ethanol futures market is capable of hedging price risk in agricultural commodity markets. The short-run asymmetric adjustments for individual prices in the nine pairs (with exception of the corn own pair underscore the importance of futures prices in the price discovery and hedging potential, particularly for ethanol futures.
\end{abstract}

Keywords: Long-run and short-run asymmetric adjustments, ethanol, agricultural products, arbitrage opportunities, hedging, widening and narrowing adjustment.

JEL Classifications: E43, Q11, Q13. 


\section{Introduction}

The rising trend in grain prices has stoked fears of food price inflation because of the forward connections of grains with many food items, ranging from meat and eggs to sweets and chocolates, to cereals and pasta. Financial analysts have attributed the hikes in grain prices to increases in the demand for ethanol. These analysts have questioned the prevailing view that the culprits underlying the rising trend in grain prices are carnivores in countries like China and India, droughts in Russia and Eastern Europe, or heavy rain in North America. Instead, they view the real culprits to be increases in the consumption of ethanol and other bio-fuels which, through the derived demand, have led to increases in prices of these goods. Some researchers view the use of commodities by financial investors (the so-called "financialization of commodities") as partly responsible for the recent price spike (Baffes and Haniotis, 2010).

This paper concentrates on the price discovery functions of four related commodities, namely bio-fuel ethanol, corn, soybeans and sugar. The first objective of the paper is to compare the price discovery performance of the ethanol futures price relative to the spot price of each of the three bio-fuel ethanol types which are traded at different commodity exchanges that are located in different countries. The second objective is to compare the performance of the spot price of each of the three associated commodities in corn, soybeans and sugar against their own futures and ethanol futures prices. The ethanol futures contracts are traded in a thin market, while those of the three associated commodities, corn, soybeans and sugar, are traded in more tightly traded markets. The second objective has become particularly significant in light of recent studies that have compared the hedging effectiveness of ethanol futures contracts against those of corn and soybeans (Dahlgran, 2009, 2010). The third objective is to determine whether positive and negative shocks, which can cause narrowing and widening of the spread between spot and futures commodities, have a different impact on the price discovery function of the futures markets for the bio-fuel and commodities of interest in this paper.

It is interesting and vital to examine the behavior of futures and cash prices of ethanol and the associated agricultural commodities in corn, soybeans and sugar, which serve as crosssubstitutes, because they share the same cropland. ${ }^{1}$ The futures contracts of these four

\footnotetext{
${ }^{1}$ For further information on the planting decisions and acreage switch between corn and soybeans, see Lin and Riley (April, 1998).
} 
commodities differ in terms of liquidity, as manifested in the respective sizes of their trading volumes and open interest positions, hedging capabilities in thinly and tightly traded markets, and integration over longer and shorter time intervals.

Comparing, for example, ethanol and gasoline futures contracts (Dahlgran, 2010), the trading volume of ethanol futures was 37 contacts per day through December 2008, with a maximum of 646 contracts per day, while the daily trading volume of gasoline futures contracts was 134,211 contracts, with a maximum of 516, 000 contracts per day for the same period. ${ }^{2}$ Ethanol futures open interest is about two percent of its annual U.S. usage in March 2010, while that of gasoline futures is nine percent for the corresponding period. A futures contract's trading volume should reach a threshold to suit both hedgers and speculators so that price risk can be passed between them without a high pricing penalty. Thus, some of these commodities, such as ethanol, have thin markets while others, like corn, do not.

The contracts of these commodities are also different in terms of their hedging effectiveness. Some studies have shown that ethanol futures contracts are hypothetically superior hedgers than others, despite their thin cash markets (Dahlgran, 2009). An ethanol futures contract is an efficient hedging instrument as it commands a relatively high risk premium through its futures price, reflecting the broader conditions in the deeper swaps market which uses the futures price, as well as in the futures market. Dahlgran (2009) also found that an ethanol futures contract is hypothetically superior in hedging the ethanol price risk than the gasoline futures contracts, as shown in Franken and Parcell (2003). Dahlgran's (2009) results also demonstrated that corn crushing hedge, using corn and ethanol futures, is effective and can provide price risk management capabilities that are comparable to those provided by the soybean crush hedge.

As futures contracts are prime in managing price risk of storable commodities, which are subject to unpredictable factors, one would expect that a predictive relationship exists between the futures and spot prices of these commodities. Thus, the movements of these prices present an interesting case for the application of cointegrating relationships in order to determine which futures price provides a prediction of the spot price in the future, or vice-versa. Consequently, spot market participants can use futures contracts as a price risk management tool to hedge

\footnotetext{
${ }^{2}$ This paper focuses on ethanol rather than gasoline because of the larger literature on the latter and the increasing interest in the former.
} 
against risk in these ethanol and agricultural commodity markets. However, both futures and spot markets are likely to have different long- and short-run adjustments to long-run equilibrium in the case of spread widening after negative shocks and spread narrowing after positive shocks. This approach will allow us to examine the hedging capabilities of the futures contracts under the widening and narrowing regimes. To the best of our knowledge, such adjustments have not yet been addressed in the symmetric adjustment literature on bio-fuels and agricultural commodities. This important issue will be pursued in the paper.

The remainder of the paper is organized as follows. Section 2 provides a review of the literature, Section 3 presents a description of the data, Section 4 discusses the methodology, Section 5 analyses the empirical results, and Section 6 gives some concluding comments.

\section{Review of the Literature}

The literature has investigated the symmetric (or linear) cointegrating relationship between spot and futures prices for the commodities under consideration in this paper. Garbade and Silber (1982) investigated the price movements and price discovery function in the spot and futures markets for seven storable commodities, including corn, wheat, oats, orange juice, copper, gold and silver. Their findings indicate that, in general, futures dominate spot price changes for most of these commodities. The evidence suggests that, for 70 percent of new information, the futures market dominates the spot markets for corn, wheat and orange juice. It seems that the authors found a similar case for gold, but the pricing power for silver, oats and copper was more divided between the spot and futures market.

Yang et al. (2001) examined the price discovery function for storable (corn. oats, soybeans, wheat, cotton and Pork bellies) and non storable (hogs, live cattle, feeder cattle) commodities. They found that although, in general, storability does not affect the futures price discovery function, futures contracts can be used as a price discovery tool in all of these markets. They also

found that large difference in trading volume of these commodities has little effect on the predictive power of their futures prices. 
Wang and $\mathrm{Ke}$ (2002) assessed the long- and short-run efficiency of the Chinese wheat and soybean futures and spot prices, with different maturities for the futures contracts. Their finding implies that that there exists a long-run relationship between futures and spot prices for soybean in China, while the short-run lead/lag relationship is weak. However, wheat futures contracts are inefficient, possibly due to government intervention in the wheat market.

Zapato et al. $(2003,2005)$ examined cointegration between New York futures price and the Dominican Republic spot price for sugar. Their empirical evidence suggests that the World Futures Sugar (WFS) price has predictive power for the spot price of a small sugar producing country. It was found that, in general, futures prices appear to play a dominant role in the price discovery mechanism. However, there appeared to be neither long-run relationships nor shortrun leads in tightly traded markets.

Mattos and Garcia (2004) investigated the relationships between spot and futures prices in six Brazilian agricultural markets (Arabic coffee, corn, cotton, live cattle, soybeans and sugar). All these markets are considered thinly traded in terms of trading volume compared with those in the USA. This paper has two surprising results relative to those of the U.S. markets. First, the thinly trade sugar futures contracts showed evidence of some degree of long-run relationships (cointegration), with the future price playing the dominant role. Second, the highly trade corn contracts showed almost no interrelations between the futures and cash prices. However, both the Brazilian sugar and corn markets have their own peculiarities that may account for these surprising results.

Although the specific results are mixed, as indicated above, Dahlgran (2009) investigated the relationship between ethanol futures contracts, which are thinly traded, and gasoline futures contracts, which are tightly trade. The evidence suggests that the former has hypothetically superior price risk hedging capabilities than the former because ethanol swaps add depth to its futures market.

Most of the literature on the price discovery function of commodities concentrates on agricultural commodities, and very few have examined this function for the ethanol market in different markets and locations. Moreover, all of the previous studies have used symmetric or linear cointegration to examine the long-run relationships, and the short-run lead/lag 
relationships between futures and spot prices using symmetric cointegration techniques and linear vector error correction (VEC) models. As a third objective, this paper will investigate the asymmetric long-run and short-run relationships using the momentum threshold autoregressive (MTAR) model and MTAR VEC models, respectively.

\section{Description of the Data}

This paper uses daily time series data on the closing spot and three-month futures prices of four highly traded and closed linked agricultural commodities, specifically bio-fuel ethanol, corn, soybeans and sugar. The sample covers the period June 23, 2006-September 8, 2010. The length of this period is dictated by the availability of data for the futures price of ethanol.

As we will use two ethanol spot prices in the USA and one in Western Europe, there are data for three spot prices. The first spot price, which will be referred to as Ethanol Spot 1, is traded on the Chicago Board of Trade (CBOT). The second spot price, hereafter Ethanol Spot 2, is the New York Harbor Ethanol traded on the New York Mercantile Exchange (NYMEX). The third spot price, referred to as ETHEUT2, is the price of the Western European (Rotterdam) ethanol T2. ${ }^{3}$ All of these prices are sourced from Thompson Reuters and are expressed in US dollars per gallon. The data on the ethanol futures price is for ethanol traded on eCBOT. Its class is CZE and is expressed in US dollars per bushel wheat (BW).

Data on corn spot and futures are sourced from Datastream, and the market is the USA. Spot corn is Corn No. 2 Yellow, and is expressed in dollars per bushel. ${ }^{4}$ Futures corn is traded the Chicago Board of Trade and its class is CC. The spot soybean data are for SOYABEANS No.1 Yellow, which is expressed in dollars per bushel. ${ }^{5}$ The futures price is traded at the Chicago Board of Trade and its class is CS. The spot sugar is the raw cane Sugar World FOB and is

\footnotetext{
${ }^{3}$ The Datastream (DS) mnemonic for Ethanol Spot 1 is ETHACHG, Ethanol Spot 2 is ETHANYH and ethanol futures is CZECS500. The T2 basis means no more import duties are applicable from the EU.

${ }^{4}$ The DS MNEMONIC is CORNUS2.

${ }^{5}$ The DS Mnemonic is SOYBEANS.
} 
expressed in dollars per pound. ${ }^{6}$ This commodity is traded in the USA. Futures sugar is traded at the New York Board of Trade and its class is NSB. ${ }^{7}$

The descriptive statistics for the spot and futures returns of the bio-fuel ethanol and agricultural commodities are given in Table 1. In general, the mean for ethanol price returns, whether spot or futures are negative, while it is positive for the spot and futures price returns for sugar, corn and soybeans. The averages are higher for spot than futures prices for corn and soybean representing a backwardation, but the opposite holds true for sugar where contango .prevails over most of its lifespan.

In terms of volatility, as defined by the standard deviation, sugar futures return has the volatility, while Western European ethanol spot indicates the lowest. This result probably reflects differences in market thinness and contract specifications. In terms of volatility between spot and futures returns, spot returns are in general more volatile than the hedging assets written on them, with the exception for sugar where futures return is more volatile than spot returns.

All of the displayed spot and futures returns have asymmetric distributions, as shown by the skewness and kurtosis statistics. All four returns are skewed to the left, indicating that the series have longer left tails (extreme losses) than right tails (extreme gains). All of the distributions have a kurtosis that is significantly higher than 3, implying that extreme market movements in either direction (gains or losses) occur in these markets, with greater frequency in practice than would be predicted by the normal distribution. The highest kurtosis is for ethanol Spot 1 followed by ethanol Spot 2, while the lowest is for corn futures. The Jarque-Bera statistics confirm the non-normal distribution of all the return series.

We use the ADF and Phillips-Perron (PP) tests to check the stationarity of all prices, as displayed in Table 2. The ADF and PP tests show that almost all eight spot and futures ethanol and commodities are I(1). Therefore, the models will be estimated in terms of the log-differences in prices to avoid spurious regressions and inferences.

\footnotetext{
${ }^{6}$ The DS Mnemonic is SUGCNRW.

${ }^{7}$ Specifically, it is SUGAR \#11.
} 


\section{Methodology}

The traditional or symmetric cointegration uses cointegration tests such as Johansen (1988), Johansen and Juselius (1990) and Enders and Granger (1998) to examine the symmetric adjustments to long-run equilibrium. In other words, the literature on convergence to long-run equilibrium does not distinguish between adjustments from below the threshold, known as spread widening, and adjustment from above the threshold, noted as spread narrowing, in response to negative and positive shocks, respectively.

There are shocks in the agricultural commodity and bio-fuel markets that may lead to different speeds of adjustment, resulting in different convergence paths for the spreads between spot and futures prices, thereby stoking different implications for hedgers, speculators and policy makers. The different speeds may be due to heterogeneity of the market participants, institutional setups and regulations, variations in information, weather conditions, changes in inventories, and profit opportunities, depending on the source of the shock. The tradability and liquidity nature of futures contracts usually affect the speeds of adjustment when the spread is widening or narrowing. The more liquid are the contracts, the more symmetric are the widening and narrowing adjustments, and vice-versa. The factors mentioned above would contribute to different convergence paths. If a variation in the speeds of adjustments can be shown, then symmetric cointegration tests are misspecified and asymmetric cointegration techniques must be used.

Enders and Siklos (2001) extended the popular two-step symmetric Engle-Granger (1987) procedure and provided a different cointegration approach that allows asymmetric adjustments towards long-run equilibrium to occur, when testing a long-run relationship between two time series. Their momentum-threshold autoregressive (M-TAR) testing procedure accounts for a non-zero threshold to reflect positive transaction costs. It has also shown good power and size properties relative to the assumption of symmetric adjustment. ${ }^{8}$ The model should have a better interpretation when the narrowing and widening of spreads have different speeds to thresholds as these spread disparities would reflect different profitable opportunities, changes in energy policy,

\footnotetext{
${ }^{8}$ According to AIC, the M-TAR model with a consistent estimate of the threshold fits the data better than the EngleGranger, TAR, and M-TAR (threshold $\tau=0$ ) models (see Balke and Fomby (1997), Chan (1993), Engle and Granger (1987), Enders and Granger (1998), Enders and Siklos (2001), and Hansen (1997) for further information on these other models).
} 
and so on. Statistically speaking, M-TAR leads to lower AIC and higher log-likelihood values than does TAR.

The Enders and Siklos (2001) procedure is the basis of the analysis in this paper (see also Enders and Granger, 1998). It will be applied to the following pairs or bivariate VARs, namely (Chicago ethanol Spot 1, Ethanol futures), (NYH ethanol Spot 2, Ethanol futures), European ethanol spot ETHEUT2, futures ethanol), (corn spot, corn futures), (soybean spot, soybean futures), and (sugar spot, sugar futures). The ethanol futures price is the eCBOT ethanol.

The first step in the Enders-Siklos (2001) framework is to estimate the following model representing the long-run relationship between the spreads for any of the ethanol and agricultural commodity pairs specified above, using ordinary least squares:

$$
P_{t}^{\text {spot }}=c+\beta_{1} P_{t}^{\text {future }}+e_{t}
$$

where $P_{t}^{\text {future }}$ and $P_{t}^{\text {spot }}$ are the logarithmic values of the futures and spot prices of ethanol, corn, soybean or sugar at time $t$. The residual, $\hat{e}_{t}$, derived from equation (1) is the spread between a spot and a futures price, which is then used to estimate the following M-TAR cointegration model of ethanol or any of the agricultural commodities:

$$
\Delta \hat{e}_{t}=\rho_{1} M_{t} \hat{e}_{t-1}+\rho_{2}\left(1-M_{t}\right) \hat{e}_{t-1}+\sum_{i=1}^{n} \gamma_{i} \Delta \hat{e}_{t-i}+u_{t}
$$

where $u_{t} \sim$ I.I.D $\left(0, \sigma^{2}\right)$ and the lagged terms of $\Delta \hat{e}$ are used to yield uncorrelated residuals. The coefficients $\rho_{1}$ and $\rho_{2}$ are expected to be negative, and their absolute values measure the speeds of the widening and narrowing spread adjustments without specifying which price, spot or futures is adjusted. If $\rho_{1}>\rho_{2}$ (in absolute value), then spread widening is faster than narrowing, or the speculators and arbitrageurs take advantage of profitable opportunities when the spread is widening faster than when it is narrowing.

The heaviside indicator function is denoted as follows: 


$$
M_{t}= \begin{cases}1 & \text { if } \Delta \hat{e}_{t-1} \geq \tau \\ 0 & \text { if } \Delta \hat{e}_{t-1}<\tau\end{cases}
$$

When $\Delta \hat{e}_{t-1}$ or the change in the spread between the spot and futures prices in a given pair for ethanol or an agricultural commodity is equal or greater than the threshold, equation (3) indicates that the spread is widening over time after a negative shock strikes the market. When $\Delta \hat{e}_{t-1}$ is less than the threshold, the spread narrows over time after a positive shock hits the market. As indicated above, the adjustment to the long-run equilibrium threshold may come from changes in either of the two prices, or both. If the threshold value, $\tau$, is assumed to be zero, it may contribute to biased estimates if there is asymmetry in the adjustment process, as indicated above. 9

Therefore, the threshold, $\tau$, is endogenously determined using Chan's (1993) method to obtain a consistent estimate of the threshold. This method arranges the values $\left\{\Delta \hat{e}_{t}\right\}$ in ascending order and excludes the smallest and largest 15 percent of observations. A consistent estimate of the threshold is the value of the parameter that yields the smallest residual sum of squares over the remaining 70 percent of observations.

Second, after the threshold, $\tau$, is estimated from equation (2), then we can split the first $\log$ differences of each pair's spot and futures price components, $\Delta P_{t-k}^{s p o t}$ and $\Delta P_{t-k}^{\text {future }}$, into two parts: $\Delta P_{t-k}^{s p o t+}$ if $\Delta \hat{e}_{t-1} \geq \tau ; \Delta P_{t-k}^{\text {spot- }}$ if $\Delta \hat{e}_{t-1}<\tau$; and $\Delta P_{t-k}^{\text {future+ }}$ if $\Delta \hat{e}_{t-1} \geq \tau, \Delta P_{t-k}^{\text {future- }}$ if $\Delta \hat{e}_{t-1}<\tau$. Thus, the change in each price component of the spread is divided into a positive change when the change in the residual is above the threshold and a negative change when the change in the residual is below the threshold.

Third, we run the following bivariate vector-error correction (VEC) system of the changes in the spot and future prices for each of the nine pairs indicated above:

\footnotetext{
${ }^{9}$ Hammoudeh et al. (2010) compared the Hansen-Seo (2002) and Enders-Siklos (2001) methods and found the latter to provide more reasonable and meaningful results.
} 


$$
\begin{aligned}
& \Delta P_{t}^{\text {spot }}=c^{\text {spot }}+ \begin{cases}\lambda^{\text {spot }} \hat{e}_{t-1}+\sum_{k=1}^{p} \alpha_{k}^{\text {spot }} \Delta P_{t-k}^{\text {spot }+}+\sum_{k=1}^{p} \beta_{k}^{\text {spot }+} \Delta P_{t-k}^{\text {future }+} & \text { if } \Delta \hat{e}_{t-1} \geq \tau \\
\lambda^{\text {spot }-} \hat{e}_{t-1}+\sum_{k=1}^{p} \alpha_{k}^{\text {spot- }} \Delta P_{t-k}^{\text {spot- }}+\sum_{k=1}^{p} \beta_{k}^{\text {spot }} \Delta P_{t-k}^{\text {future }-} & \text { otherwise. }\end{cases} \\
& \Delta P_{t}^{\text {future }}=c^{\text {future }}+ \begin{cases}\lambda^{\text {future }+} \hat{e}_{t-1}+\sum_{k=1}^{p} \alpha_{k}^{\text {future }} \Delta P_{t-k}^{\text {spot }+}+\sum_{k=1}^{p} \beta_{k}^{\text {future }+} \Delta P_{t-k}^{\text {future }+} & \text { if } \Delta \hat{e}_{t-1} \geq \tau \\
\lambda^{\text {future }-} \hat{e}_{t-1}+\sum_{k=1}^{p} \alpha_{k}^{\text {future }-} \Delta P_{t-k}^{\text {spot }-}+\sum_{k=1}^{p} \beta_{k}^{\text {future }} \Delta P_{t-k}^{\text {future }-} & \text { otherwise }\end{cases}
\end{aligned}
$$

After this MTAR-VEC model is estimated, we test the short- and long-run adjustments to the threshold. In the spot equation (4), both the above and below the long-run equilibrium speeds of adjustment $\lambda^{\text {spot }+}$ and $\lambda^{\text {spot- }}$, respectively, should be negative for the spot price to revert to the long-run equilibrium. As indicated above, if the spread, $e_{t-1}$, is negative but widening, and thus the change in this spread, $\Delta e_{t-1}$, is increasing, the spread is widening (that is, $M_{t}$ is 1 in equation (3)), and the spot price will need to increase to revert to the long-run position, so that $\lambda^{\text {spot+ }}$ needs to be negative. If the spread, $e_{t-1}$, is positive but narrowing and $\Delta e_{t-1}$ is decreasing (that is, $M_{t}$ is 0 ), then the speed $\lambda^{\text {spot- }}$ also needs to be negative, indicating that the spot price needs to fall for the spread to revert to its long-run position. In summary, if the long-run speeds of adjustment parameters in equation (4) are such that $\lambda^{\text {spot+ } \neq} \lambda^{\text {spot- }}$, then the ethanol or the agricultural spot market exhibits asymmetry in the long-run adjustment.

In the futures equation (5), both the above and below the threshold long-run speeds of adjustment for the futures price, $\lambda^{\text {future }+}$ and $\lambda^{\text {future- }}$, should be positive. Again, when $\Delta e_{t-1}$ is increasing, the spread is widening (that is, $M_{t}$ is 1 ), and the futures price will need to decrease to revert to the long-run position, so that $f^{\text {future+ }}$ needs to be positive. If the spread is narrowing $\left(M_{t}\right.$ is 0 ), then for the spread to narrow to equilibrium, $\lambda^{\text {future- }}$ needs to be positive, indicating that the futures price has to increase. Again, if the long-run adjustment parameters for the futures price in equation (5) are not equal, that is $\lambda^{\text {future }+} \neq \lambda^{\text {future- }}$, then the futures price exhibits asymmetry in the long-run adjustment.

If $\lambda^{\text {future }+}>\lambda^{\text {spot+ }}$ in absolute value, and at least the former is statistically significant, then the futures price leads in the price discovery process during spread widening. This implies that 
the futures price processes negative information faster than does the spot price. In this case, the futures contracts can be used as a price risk hedge for the spot prices during spread widening. This means hedgers and speculators have faith in the futures market capabilities to provide enough liquidity to transfer price risk from hedgers to speculators after negative shocks hit the markets. On the other hand, if $\lambda^{\text {future+ }}<\lambda^{\text {spot+ }}$ in absolute value, then futures contracts do not provide hedges in the price risk management, which could possibly be due to the thinness and lack of liquidity in the futures market. The same analogy applies for the case of spread narrowing when $\lambda^{\text {future- }}>\lambda^{\text {spot- }}$ and vice-versa.

The short-run adjustment of the spot prices, which is governed by the parameters, $\alpha_{k}^{\text {spot+ }}$, $\alpha_{k}^{\text {spot- }}, \beta_{k}^{\text {spot }+}$, and $\beta_{k}^{\text {spot- }}$ (for lags $k=1,2, \ldots, p$ ), may come, respectively, either from its own history of up and down lagged dynamics or from the lagged effects of changes up and down in the futures prices. If either the short-run adjustment parameters $\alpha_{k}^{\text {spot }+} \neq \alpha_{k}^{\text {spot- }}$ or $\beta_{k}^{\text {spot }} \neq \beta_{k}^{\text {spot- }}$ or both in equation (4), the spot prices display asymmetry in short-run adjustment. Equation (5)

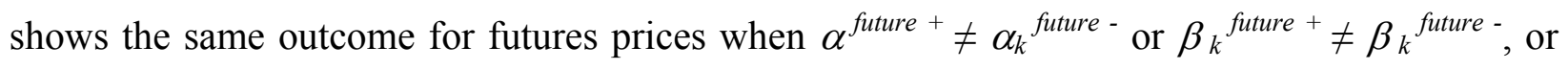
both.

\section{Empirical Results}

The methodology will be implemented in steps to obtain the empirical results. We will discuss first the possibility of the presence of cointegration between the spot and futures prices in each of the nine price pairs for all the three groups of ethanol and grains using the Enders-Siklos (2001) method. The nine price pairs are: (Chicago ethanol Spot 1, eCBOT ethanol futures), (NYH ethanol Spot 2, eCBOT ethanol futures), (Western European Rotterdam spot, eCBOT ethanol futures), (corn spot, corn futures), (soybean spot, soybean futures), (sugar spot, sugar futures), (corn spot, eCBOT ethanol futures), (sugar spot, eCBOT ethanol futures), and (corn spot, eCBOT ethanol futures). If cointegration exists, then we test whether the long-run adjustment of each spread is symmetric or asymmetric for each of the nine possible pairs. We end this section by discussing the results of the estimated bivariate asymmetric error-correction models, and examine which individual price, spot or futures or both, would do the adjustments in 
the short- and long-run. We will focus on the asymmetric VEC model that gives more significant results.

\subsection{Results of the Threshold Cointegration and Asymmetry Tests}

First, we estimate the respective thresholds for each of the nine bivariate cointegration spot-futures price models. Then we will examine the cointegration results to discern whether the spread for each bivariate cointegration model, as expressed in equation (2), might be symmetrically or asymmetrically cointegrated. Therefore, we will explore the long-run comovement of the spread between the spot and futures prices in each pair of the bio-fuel and grains, while allowing for asymmetric adjustments towards the long-run equilibrium. As explained above, the difference in speeds of adjustments toward the threshold is due to variations in profitable opportunities above and below the threshold which may be influenced by fundamental, transitory and/or contract factors.

The long-run equation (1) is estimated for each of the nine pairs of spot and futures markets, and the resulting residual from the estimation of this equation is used to estimate the respective thresholds, using the Enders-Siklos (2001) procedure, as in equation (2). The results for the estimated thresholds and cointegration hypotheses are provided in Tables 3-A to 3-C and their asymmetric adjustment paths are displayed in Figure 1. The estimated thresholds for the three ethanol types, three agricultural commodities and three ethanol/commodity hybrids are relatively small, with that for New York Harbor ethanol (Spot 2) being the highest. This empirical evidence may suggest that there are greater fiction and transaction costs at the NYH ethanol market than at the other markets. Among the three ethanol types, the estimated thresholds for the two American ethanol pairs that contain the Chicago and New York Harbor are much larger than for the pair that includes the Western European (Rotterdam) ethanol. This finding may indicate that there is greater friction in the two American markets than in the Western European market. Thus, it may reflect differences in liquidity, thinness and contract specifications between the American and European ethanol spot markets.

The estimates of the respective bivariate threshold (MTAR) cointegration models given in equation (2) for the ethanol and agricultural commodity pairs or spreads, using the non-linear Enders-Siklos (2001) cointegration method that tests for symmetric or asymmetric cointegration 
for these markets, are also provided in Tables 3-A to 3-C. ${ }^{10}$ As expected, the $\Phi_{\mu}$-statistic for each of these nine bivariate models exceeds its respective critical value (Enders and Siklos, 2001). In this case, we reject the null hypothesis of no cointegration (that is, $\rho_{1}=\rho_{2}=0$ in equation (2)) or no long-run relationships between the paired spot and futures prices. This means the paired spot and futures prices move together over time toward the long-run equilibrium, and hence are cointegrated. This result implies that the spot and futures contracts do not minimize portfolio risk when both are included in a diversified portfolio as their markets are not efficient as a result of being cointegrated. This is not entirely surprising as the spot is the underlying asset for the futures of the same commodity for the first six pairs and for the three related commodity hybrids.

However, when we test whether the spread adjustment to the long-run equilibrium is symmetric (the null hypothesis is $\rho_{l}=\rho_{2}$ in equation (2)) or asymmetric for each pair, the results are similar except for the Western European ethanol. That is, when we test whether the spot and futures prices for each commodity move together toward the long-run equilibrium at different speeds relative to being below or above the threshold, we reject the null hypothesis of symmetric adjustment in favor of asymmetric adjustment for all the pairs, except for the pair that contains the Western European spot ethanol which seems to have a symmetric adjustment. This suggests that the profitable opportunities in the European ethanol market are the same, regardless of the source of the shock. Combining the adjustment symmetry with the lowest threshold results, the European ethanol market appears to have more tradable and liquid contracts than the other markets. The asymmetric adjustment in the American markets implies that the profitable arbitrage opportunities are different, depending on whether the shock is positive or negative. Figure 1 traces the adjustment trajectories for the nine spreads, including the one of the symmetric Western European spread.

The results also demonstrate that the asymmetric adjustment to the long-run equilibrium is significant for all the spreads (excluding the symmetric European ethanol) in the case of spread narrowing but taking place at different speeds, with the hybrid (corn spot, ethanol futures) pair having the highest speed. This empirical evidence implies that the corn-ethanol hybrid spread offers the highest profitable opportunities in the aftermath of positive shocks. It attests to the ethanol futures capability of hedging corn spot prices, which is consistent with some studies

\footnotetext{
${ }^{10}$ We also estimated the TAR model but found the results of the M-TAR to be more reasonable, as in other studies.
} 
in the literature. However, the results for the asymmetric adjustments toward the equilibrium in the case of spread widening are mixed. These below-the-threshold adjustments following the incident of a negative shock are significant only for the spreads: Spot1-futrues ethanol, spotfutures corn and spot-futures soybeans, and for all the hybrid pairs, with the Spot 1-futures ethanol having the fastest while the hybrids having the slowest spread widening. This finding underscores the relative importance of profitable opportunities in the ethanol market after a negative shock that causes a contango in the corn market.

With regard to the three bio-fuel ethanol types, the estimated bivariate MTAR cointegration ethanol models for the three ethanol price pairs in the first group show different speeds and directions of adjustment towards the long-run equilibrium (Table 3-A). The difference is also reflected in the adjustment trajectory paths as shown in Figure 1. This finding implies that these ethanol markets offer different arbitrage opportunities. The price pair that contains Spot 1, which is traded at the Chicago Board of Trade, shows statistically significant widening and narrowing spread adjustments. However, the asymmetric adjustment for this spread is much faster for widening after a negative shock strikes than for narrowing after a positive shock as displayed clearly in Figure 1. That is, the adjustment is faster after backwardation than contango. This empirical evidence suggests that the profitable arbitrage opportunities for this ethanol spread is greater during spread widening than during spread narrowing.

In the case of the two other ethanol pairs, where one pair contains the New York Harbor ethanol Spot 2 and the other includes the Western European spot, the asymmetric and symmetric adjustments, respectively, are significant only for narrowing which starts from above the threshold. The spread narrowing adjustment for the pair that contains the Spot 2 is slightly faster than that for the pair that contains the Chicago Spot 1. The Western European ethanol pair adjusts very slowly during narrowing and does not adjust during widening. This price pair shows the least profitable arbitrage opportunities. In summary, if there is good news about bio-fuel ethanol, whether in terms of more favorable future green energy policy, economy or weather, and the spread is widening and the market entered a backwardation, traders are more active in seeking profitable opportunities in the Chicago market than in New York Harbor and Western European Rotterdam ethanol markets. 
The asymmetric spread adjustments to the long-run equilibrium for the own spot and futures pairs of sugar, corn and soybeans of the second group also show different patterns (Table 3-B). There are both significant spread widening and narrowing in the case of corn and soybeans, but only significant narrowing for sugar. This evidence suggests that the corn and soybean markets are generally more liquid than the sugar market. The corn spread shows the strongest adjustment during narrowing. Figure 1 indicates clearly that the sugar spread has no convergence to long run equilibrium in the after math of a negative shock and widening takes place.

Interestingly, all three ethanol spreads show some significant adjustment during narrowing, but at a much lower speed than for corn market, which is most likely due to their relative greater thinness and less liquidity and depth. The soybean spread demonstrates the weakest narrowing adjustment. This is of course indicative of the differential profitable opportunities, warranting different trading strategies for this spread.

The estimates of the asymmetric cointegration hybrid model for the third group are given in Table 3-C. The results show statistical significance for all pairs in this group. Most of the spreads that mix the ethanol futures price with the spot price of each of the three agricultural commodities show significant adjustments to long-run equilibrium during both widening and narrowing. Figure 1 shows very different convergence/divergence paths of these three hybrid spreads. Interestingly, it seems that traders are more active in trading the spread that pairs ethanol futures with corn spot prices. This spread, followed by the ethanol futures/soybean spread, shows the fastest adjustment to equilibrium during narrowing. These results demonstrate that the ethanol futures price has varying hypothetical hedging capabilities for the three agricultural commodities, but the greatest for corn spot, for which it is a very close complement.

A positive finding of asymmetric cointegration with the threshold adjustment (with the exception of the spread that contains the West European ethanol spot) justifies and paves the way for estimation of an asymmetric error-correction model for the futures and spot price returns of each of the markets, as will be shown in the next subsection. ${ }^{11}$ In this model, we can move forward another step by identifying which individual price (spot, futures or both) reverts to

\footnotetext{
11 According to AIC, the M-TAR model with a consistent estimate of the threshold fits the data better than the Engle-Granger, TAR, and M-TAR ( $\tau=0)$ models (see Balke and Fomby (1997), Chan (1993), Engle and Granger (1987), Enders and Granger (1998), Enders and Siklos (2001), and Hansen (1997) for further information on these other models).
} 
equilibrium from below (spread widening) or above (spread narrowing) the threshold in the short- and long- run under the Enders-Siklos method. ${ }^{12}$

\subsection{Results of the M-TAR VEC Models}

As it has been demonstrated that the threshold cointegration exists in all price pairs for the ethanol types, agricultural commodities and hybrids, then the bivariate threshold vector errorcorrection (VEC) model should be used for each of these pairs. That is, as cointegration has been found to be asymmetric, we should estimate the asymmetric bivariate (M-TAR) vector errorcorrection (VEC) model, as defined in equations (4) and (5).

Bivariate asymmetric VEC models are estimated to investigate the asymmetric individual behavior of the spot and futures price returns for each of the ethanol, agricultural and hybrid markets in the short- and long-run. The VEC model allows us to determine which of the spot and futures prices leads in the price discovery process in the short- and long-run. If the futures price leads in the price discovery, then futures contracts can be used as a hedge in managing price risk. Such a finding means that hedgers and speculators believe that the futures market is of certain depth and liquidity that allows the transfer of price risk from the former to the latter.

Moreover, the asymmetric VEC model differs from the conventional (symmetric) VEC model by allowing asymmetric long-run and short-run adjustments for the individual spot and futures prices to take place from different directions of the threshold and toward the long-run equilibrium. Such a specification recognizes the fact that traders respond differently to profitable arbitrage opportunities in the long run (and maybe even in the short run), depending on whether the individual prices lead to a narrowing or widening, or the spot and futures prices are increasing or decreasing in each pair. In summary, the asymmetric VEC model helps to determine whether the futures price leads the spot price during widening when the shock comes from below the threshold, and during narrowing when the shock emanates from above the threshold, and consequently whether the futures contracts are a useful hedge after these different shocks occur.

\footnotetext{
12 The results for the individual price adjustments from the Hansen-Seo threshold cointegration method are available upon request, but the results from the two methods are not comparable as the threshold and other variables are specified differently.
} 
The estimates of the bivariate M-TAR error-correction models for the ethanol types, agricultural markets and hybrids are given in Tables 4-A to 4-C. The results suggest that under the joint long- and short-run hypothesis and also under the short-run hypothesis, both the spot and futures prices in general make the adjustment toward the equilibrium The exceptions are ethanol futures in the pair (ethanol Spot1, ethanol futures), corn spot and futures in the pair (corn spot, corn futures) and sugar spot in the hybrid pair (sugar spot, ethanol futures). Under the long-run hypothesis, the results are more mixed and less significant than the previous two hypotheses. Ethanol Spot 1 in the pair (ethanol Spot1, ethanol futures), ethanol futures in the ethanol pair that contains ethanol Spot 2, sugar futures in the own spot-futures sugar pair, sugar spot in the sugar hybrid pair, corn spot and ethanol futures in the corn hybrid pair and soybean spot in the soybean hybrid pair are significant under the long-run hypothesis. Futures price returns seem to be not as significant under the long-run hypothesis as under the previous two hypotheses.

The empirical evidence on that the long-run asymmetric adjustment for the individual spot and futures prices in these models suggest that this adjustment is only significant for the two ethanol types and sugar, but not for corn and soybean. With respect to the ethanol pairs that contain Chicago Spot 1 and NYH Spot 2, the evidence shows that in the first pair only the spot price leads in the price discovery in the long-run and makes the widening and narrowing adjustments, while in the second pair the futures leads and adjusts during widening but the spot adjusts during narrowing (Table 4-A). This implies that the futures price provides the futures hedge against price risk in the long run only in the NYH market but not in the Chicago market. It is possible that the NYH futures ethanol market has greater depth on its own and is supplemented by the depth of the ethanol options or swaps market. In the Chicago market, the depth seems to lie in the spot market. The results presented here give a more detailed and discriminating explanation than does the symmetric literature on ethanol.

In terms of the individual price adjustments for the three agricultural commodities, the empirical evidence suggests that only the sugar futures price is significant during narrowing, and moves the adjustment towards the long-run equilibrium when the shocks are positive. This finding demonstrates that the sugar futures price may have a price risk hedging capability (see Table 4-B). 
In the hybrid markets, the individual price adjustment is more diversified and significant than in the first two groups. In the corn hybrid market, the spot leads the futures in both narrowing and widening. In the sugar and hybrids, only the spot adjusts and leads during narrowing.

Finally, we present the individual price asymmetric adjustments in the short-run for the nine bivariate VEC models. The overriding conclusion suggests that the futures price plays the leading role in price discovery and potential hedging in the short run, with the exception of the corn futures in the corn market. ${ }^{13}$ However, this leading price role of the futures price may happen during widening or narrowing, depending on the pairs of spot and futures under in mind.

The short-run causal relationships for the individual prices indicate that both spot and futures ethanol prices in each of the two pairs that contain Spot 1 and Spot 2 prices have lagged bidirectional dynamics during widening. However, the futures price plays a stronger role in the price discovery function, indicating that these futures contracts have hedging capabilities particularly after negative shocks strike after the incident if a heavy shock strikes. The short-run, differently lagged dynamics indicate these prices process incremental information.

Analogous to the ethanol dynamics in the short-run in the previous bivariate VEC models, the spot-futures sugar market displays similar lagged, short-run bidirectional feedback between the futures and spot prices. The difference is that the sugar market experiences stronger feedback during both widening and narrowing than the ethanol markets do. Still, in both asymmetric adjustments the futures price plays a stronger price discovery role than does the spot price

Unlike the ethanol and sugar markets, the corn spot-futures market has surprisingly unidirectional adjustments running from the spot to the future price during both widening and narrowing. Therefore, in this grain market the futures prices doesn't lead in the price discovery regards whether adjustments comes from below or above the threshold, and thus may not have potentially effective hedging capability.

\footnotetext{
13 The tables cannot be presented here because each price, whether during widening or narrowing, has more than 20 lags. However, they are available on request.
} 
The short-run dynamics for the spot-futures soybean resembles those of the sugar market but to a somewhat lesser degree. There are lagged, short run bidirectional feedback relationships between the spot and futures soybean price during both widening and narrowing. However, the futures price plays a stronger role during narrowing while the spot price serves a stronger role during widening. Therefore, the short-run asymmetric results for this soybean market are more mixed than for the sugar market.

In the hybrid sugar spot-ethanol pair, the short-run dynamics between the sugar spot price and ethanol futures are weak. There is a unidirectional relationship manifested in the ethanol futures price leading the sugar spot price during narrowing only, underlying the role of ethanol 1 futures in the price discovery and potential hedging capability. The ethanol futures price does the spread narrowing by moving up.. A trading strategy that is on averaged on taking a long position in ethanol futures contact is perhaps the right strategy.

The stronger short-run asymmetric adjustment between the corn spot price and the ethanol futures price is during narrowing, with the ethanol futures having the upper lead. The relationship between them during widening exists but not strong. The trading strategy recommendation in this hybrid pair is still the same as for the (corn spot, ethanol futures) pair. Finally, the short-run dynamics and the trading strategy for the hybrid soybean spot-ethanol futures markets are similar to the one for the (corn spot, ethanol futures)

\section{Conclusion}

The paper examines the asymmetric adjustments for the spreads and the individual spot and futures prices for the three groups of bio-fuel ethanol types, related grains (corn, soybean and sugar) and hybrids of the ethanol futures and grains spot. The first group includes prices of Chicago ethanol spot (Spot 1), NYH ethanol spot (Spot 2), eCBOT ethanol futures, and Western European (Rotterdam) ethanol spot. The second group is comprised of the own spot and futures prices of corn, soybean and sugar. The third group is a hybrid, which consists of a mixture of price pairs of the eCBOT ethanol futures and a spot price of each of the agricultural products.

The results show clearly that the adjustment for the ethanol spread that contains the European ethanol spot is symmetric, while it is asymmetric for the two American ethanol 
spreads, reflecting greater liquidity and tradability and absence of threshold effects in the European market. The America ethanol price spreads adjust asymmetrically to long-run equilibrium during both widening and narrowing.

This analysis also enables us to examine both the asymmetric adjustments of the spreads and the individual price movements in the short- and long-run for all American ethanol, grains and hybrid markets for the purposes of determining the availability of different profitable arbitrage opportunities related to varying shocks. It also enables us to understand the capability of price discovery and risk price hedging in markets that have different liquidity and depth. Interestingly, the empirical evidence demonstrates that the adjustments are more significant and consistent for the spreads than for the individual spot and futures price movements. In other words, traders may find buying and selling the spreads to be more transparent than trading with the individual spot and futures contracts.

Traders are more active in trading the spread of the pair that contains the Chicago ethanol spot (Spot 1) during widening (contango) that follows a negative shock than during narrowing after the incident of a positive shock. On the other hand, traders are also active and find greater profitable opportunities in the spread that contains the NYH ethanol spot when there is narrowing (backwardation) and the shock is positive. This empirical finding may suggest that those traders would find more profitable opportunities in the NYH spread and not in the Chicago spread following good news related to energy policies, such as President Obama's green put policy which encourages the use of bio-fuels and green energy. However, those ethanol spreads would require different trading strategies.

Among the three grains spreads, corn seems to offer traders the most profitable opportunities in trading spreads during narrowing, while the soybean spread undertakes the fastest asymmetric adjustment and provides the most profitable opportunities during widening. Interestingly, different shocks affect the grains spreads differently and give rise to different profitable opportunities. This finding also underscores the difference in the pertinence of trading strategies for these two commodities in response to different shocks.

As far as the hybrid spreads are concerned, the results show that they are significant during both widening and narrowing, implying that an active price discovery and hedging in these hybrid markets are possible. The speeds of adjustment are highly diversified across hybrids and during widenings and narrowings, with corn having the strongest spread widening 
adjustment. These findings underscore the special impacts of narrows after negative shocks strike in this group.

In terms of individual spot and futures price adjustments in the long-run, the results are mixed and not as transparent as for the spreads. However, it is worth noting that the corn futures price undertakes long-run asymmetric adjustment during narrowing, underscoring the importance of futures price leadership and price risk hedging capabilities in the corn market. The individual sugar and soybean prices do not possess such characteristics. This result flies in the face of the symmetric adjustment literature that has found these characteristics for the individual prices in the grains markets. It underlines the importance of having viable swaps and options markets for these grains to support and deepen their futures markets.

The pairs of hybrid groups are the most statistically significant of all the groups when in terms of both spread widening and narrowing, thereby underscoring the strength of the long-run relationships these grains have with the ethanol futures price. Hypothetically, it indicates the importance of hedging the spot prices of these agricultural commodities with ethanol futures contracts. It may also send an important message to the hesitant ethanol hedgers and speculators that the ethanol futures market has the capability of hedging price risk in agricultural commodity markets.

The overriding conclusion for the individual spot and futures price asymmetric adjustments in the short run suggests that the spot price plays the leading role in the price discovery and potential hedging for all most all pairs, particularly during narrowing. 


\section{References}

Baffes, J. and Haniotis, T. (2010). "Placing the 2006/08 commodity price boom into perspective." Policy Research Working Paper 5371, World Bank. http://wwwwds.worldbank.org/external/default/WDSContentServer/IW3P/IB/2010/07/21/000158349 2 0100721110120/Rendered/PDF/WPS5371.pdf.

Balke, N. and Fomby, T. (1997). Threshold cointegration. International Economic Review $38,627-643$.

Chan, K. (1993). "Consistency and limiting distribution of the least squares estimator of a threshold autoregressive model." Annals of Statistics 21, 520-533.

Dahlgran, R.A. (2009). "Inventory and transformation hedging effectiveness in corn crushing.” Journal of Agricultural and Resource Economics 34, 154-171.

Dahlgran, R.A. (2010). "Ethanol futures: Thin but effective? Why?" Proceedings of the NCCC-134 Conference on Applied Commodity Price Analysis, Forecasting and Market Risk Management. Saint Louis, Missouri. http://www.farmdoc.illinois.edu/nccc134.

Enders, W. and Granger, C. (1998). "Unit-root tests and asymmetric adjustment with an example using the term structure of interest rates." Journal of Business and Economic Statistics. 16, 304-311.

Enders, W. and Siklos, P.L. (2001). "Cointegration and threshold adjustment." Journal of Business and Economic Statistics 19, 166-176.

Engle, R. and Granger, C. (1987). "Cointegration and error-correction representation, estimation and testing." Econometrica 55, 251-276.

Franken, J.R.V. and Parcell, J.L. (2003) "Cash ethanol cross-hedging opportunities.” Journal of Agricultural and Applied Economics 35, 509-516.

Garbade, K. and Silber, W.L. (1982). "Price movements and price discovery in futures and cash markets.” Review of Economics and Statistics 64, 289-297. 
Hammoudeh, S., Chen, L.-H. and Fattouh, B. (2010). "Asymmetric adjustments in oil and metals markets.” Energy Journal 31, 183-203.

Hansen, B. (1997). "Inference in TAR models." Studies in Nonlinear Dynamics and Econometrics 1, 119-131.

Hansen, B.E. and Seo, B. (2002). "Testing for two regime threshold cointegration in vectorcorrection models." Journal of Econometrics 110, 293-318.

Johansen, S. (1988). Statistical analysis of cointegrating vectors. Journal of Economic Dynamics and Control 12, 231-254.

Johansen, S. and Juselius, K. (1990). Maximum likelihood estimation and inferences on cointegration-with application to demand for money. Oxford Bulletin of Economics and Statistics 52, 169-210.

Lin, W. and Riley, P.A. (1998). Rethinking the soybeans-to-corn price ratio. Is it still a good indicator for planting decisions?", Economic Research Service, US Department of Agriculture, Washington, D,C., April, 1-33.

\section{http://www.ers.usda.gov/publications/corn/crnprato.pdf}

Mattos, F. and Garica, P. (2004). "Price discovery in thinly traded markets: Cash and futures relationships in Brazilian agricultural futures markets." Proceedings of the NCCC-134 Conference on Applied Commodity Price Analysis, Forecasting and Market Risk Management. Lois, Missouri. http://ageconsearch.umn.edu/bitstream/19019/1/cp04ma02.pdf

Wang, H.H. and Ke, B. (2002). Efficiency test of agricultural commodity futures markets in China." Washington State University.

\section{http://www.bm.ust.hk/ ced/Holly\%20H\%20WANG.pdf}

Yang, J., Bessler, D.A. and Leathan, D. (2001). "Asset storability and price discovery in commodity futures market: A new look”. Journal of Futures Markets 21, 279-300. 
Zapato, H.O., Fortenberry, T. R. and Armstrong, D. (2003). "Price discovery in the futures and cash market for sugar." Paper presented at the Southern Agricultural Economics Association Annual Meeting, Mobile, Alabama, February, 1-5.

Zapato, H.O., Fortenberry, T.R. and Armstrong, D. (2005). "Price discovery in the world sugar futures and cash markets: Implications for the Dominican Republic." Staff Paper \# 469, University of Wisconsin, Madison, Wisconsin.

http://www.aae.wisc.edu/pubs/sps/pdf/stpap469.pdf 
Figure 1: Asymmetric Adjustment Paths for the Spreads

\section{Ethanol spot1 v.s. Ethanol futures}

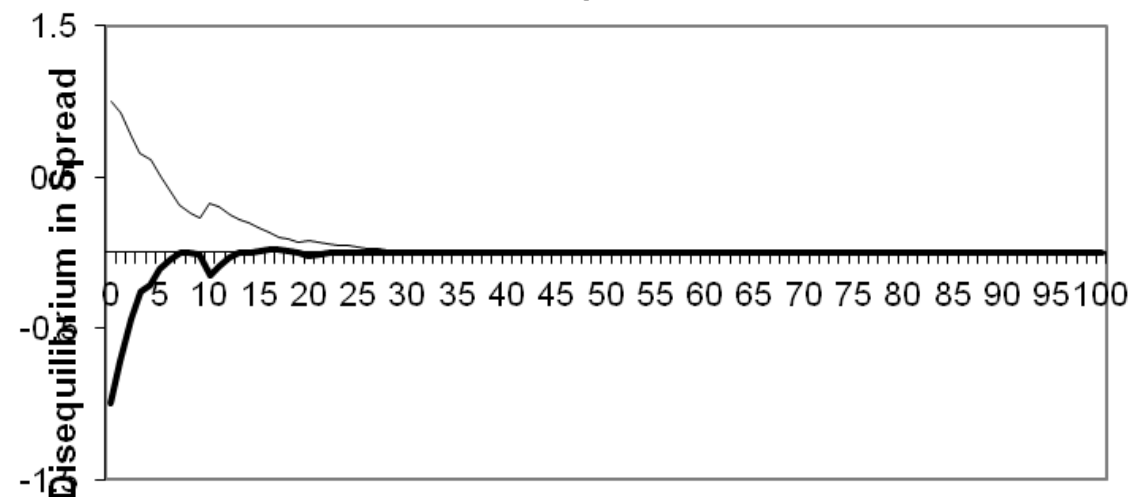

Ethanol spot2 v.s. Ethanol futures

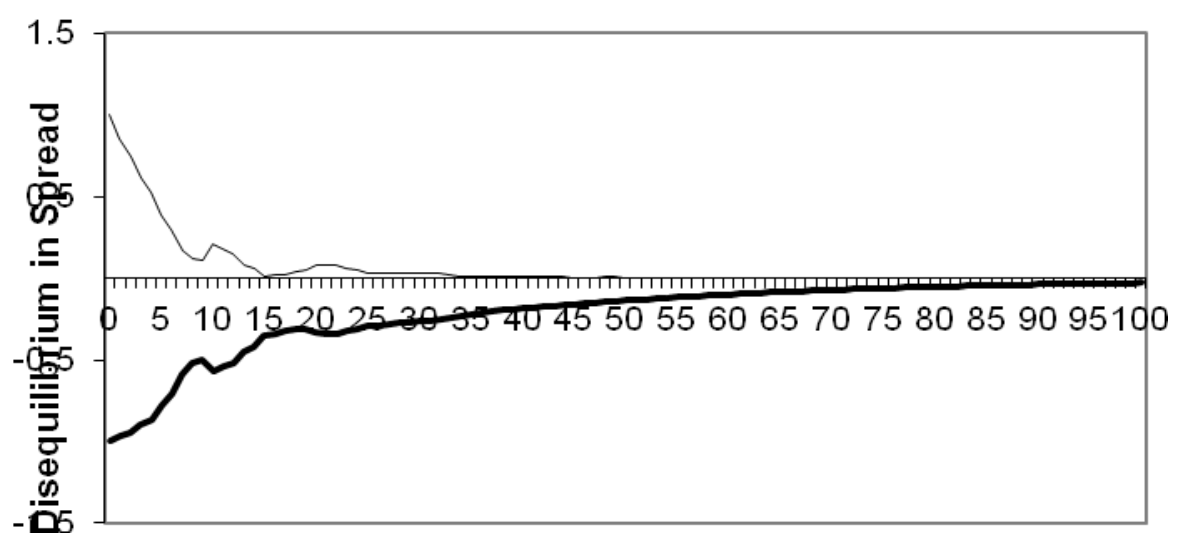

European Ethanol spot v.s. Ethanol futures

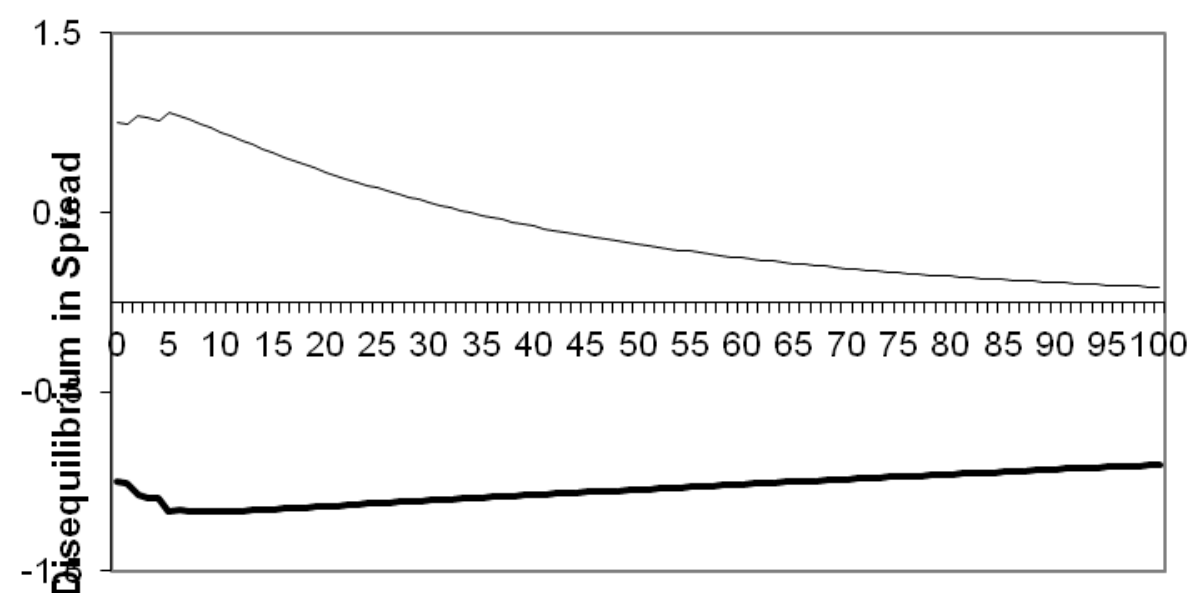


Sugar spot v.s. Sugar futures

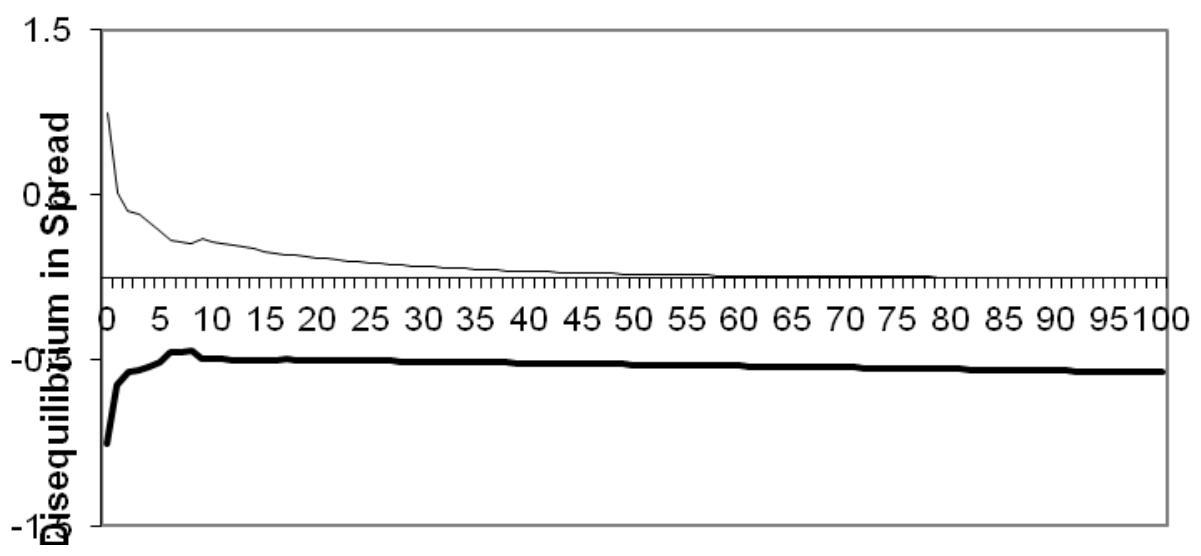

Corn spot v.s. Corn futures

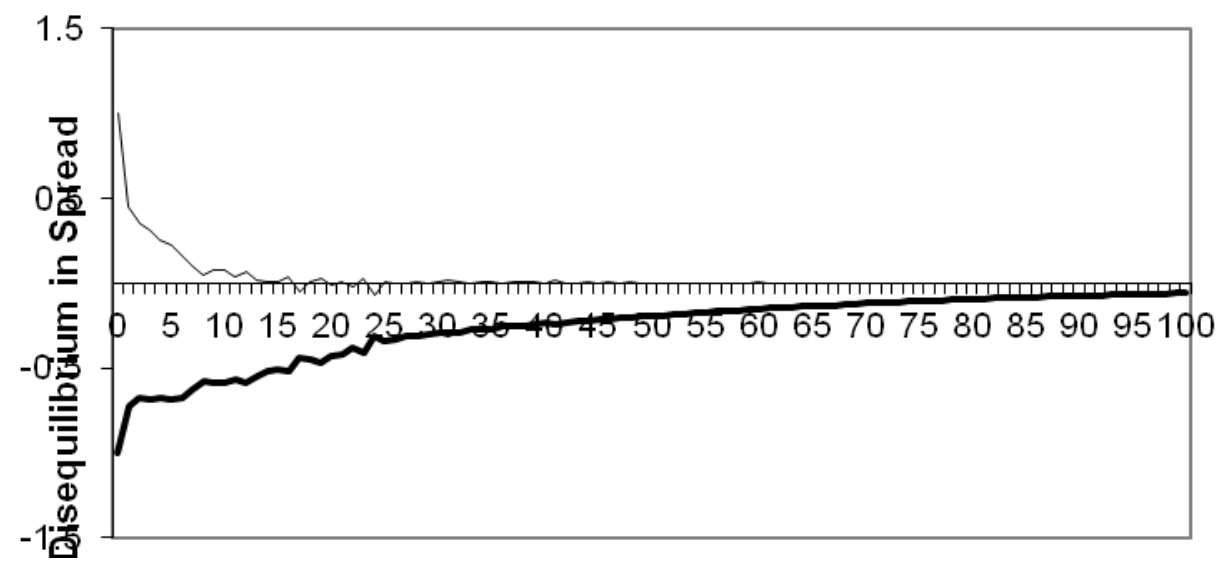

Soybean spot v.s. Soybean futures

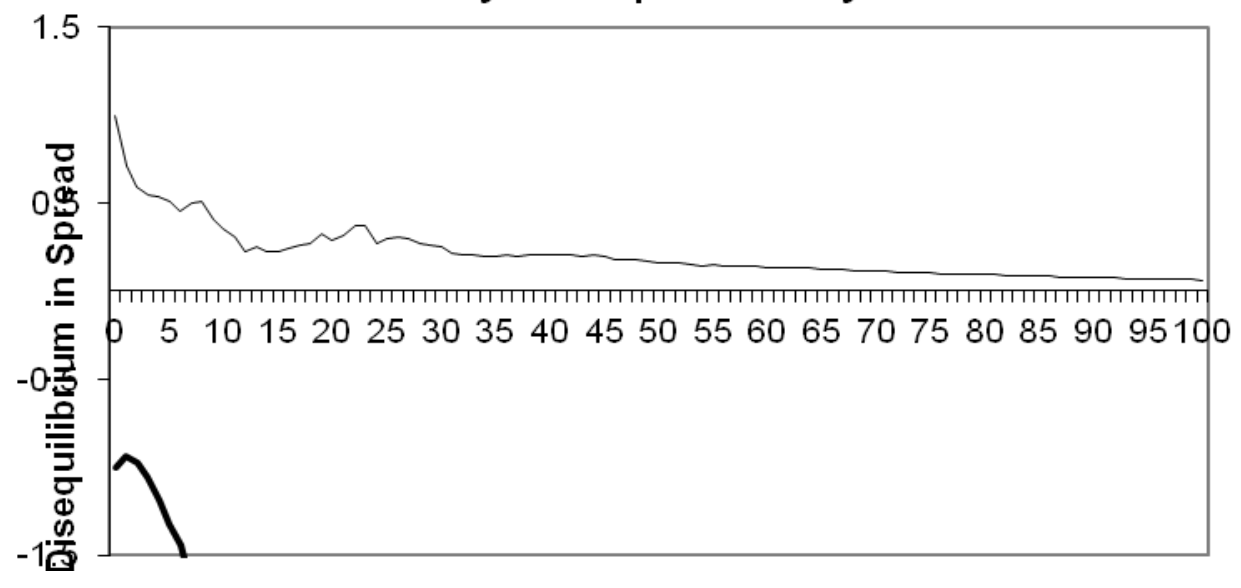




\section{Sugar spot v.s. Ethanol futures}

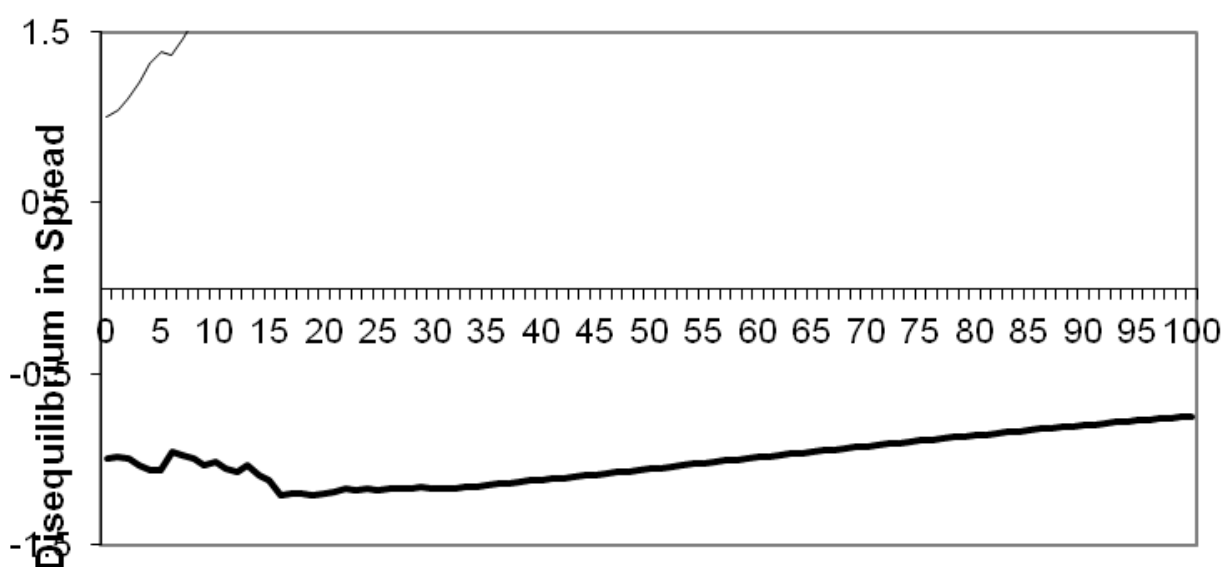

Corn spot v.s. Ethanol futures

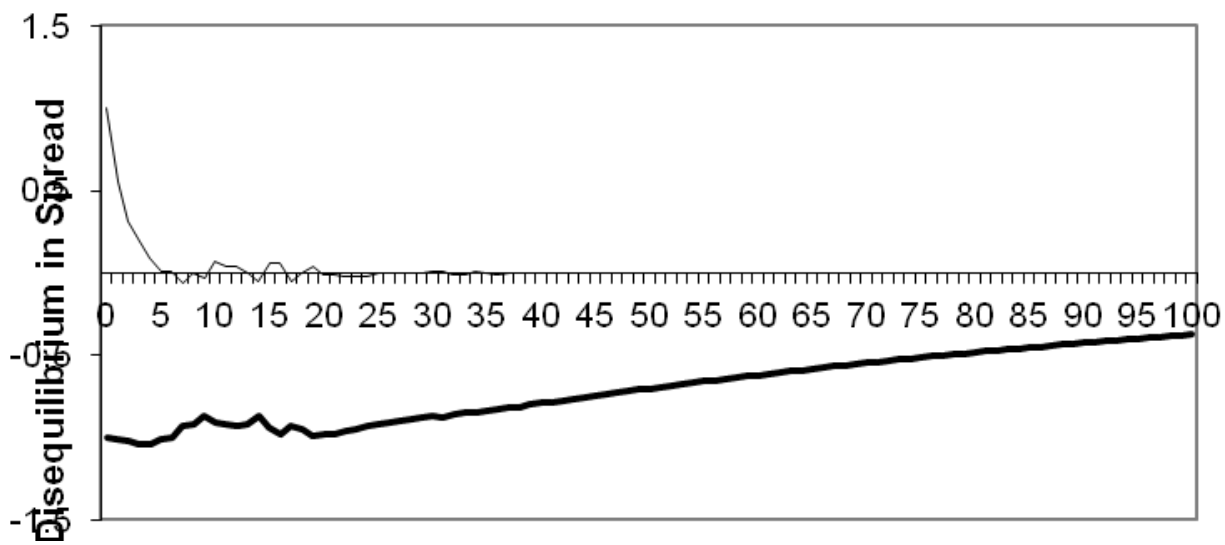

Soybean spot v.s. Ethanol futures

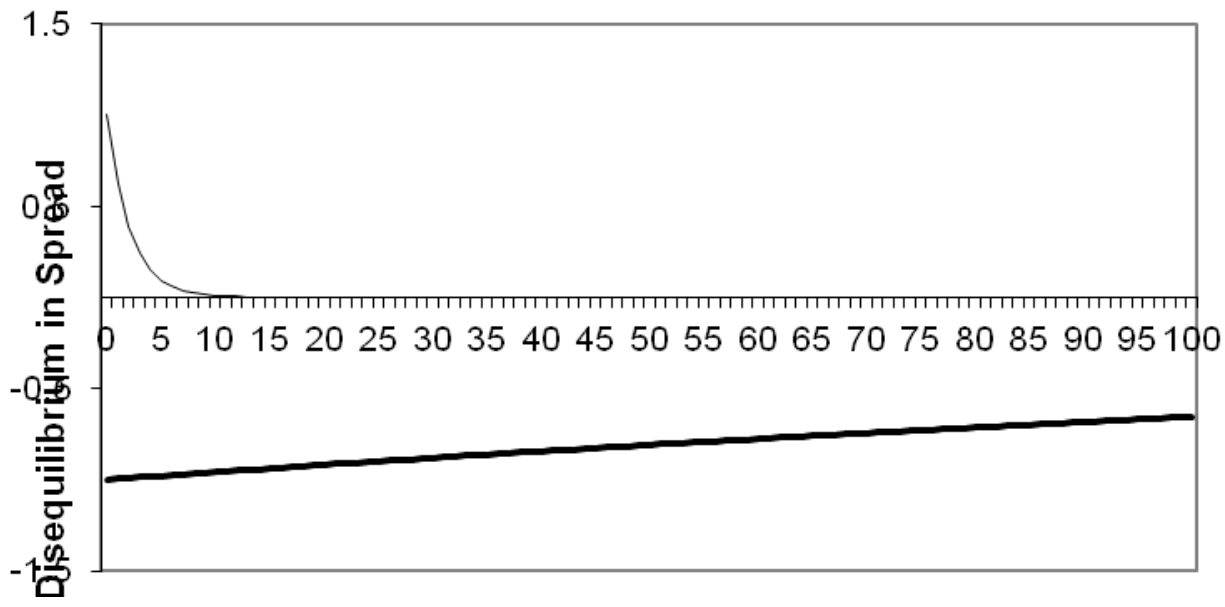

Notes: Ethanol Spot 1 refers to spot ethanol at CBOT, while Spot 2 represents the NYH spot ethanol. All the spreads are asymmetric except the one that contains the European spot ethanol. In each graph, the top half illustrates the adjustment path after a positive shock, while the bottom half illustrates the speed of adjustment after a negative shock. 
Table 1: Descriptive Statistics for Ethanol/Commodity Futures Returns

\begin{tabular}{lllllllll}
\hline Variables & & Mean & Std. Dev. & Skewness & Kurtosis & $\begin{array}{l}\text { Jarque- } \\
\text { Bera }\end{array}$ & $\begin{array}{l}\text { Probability } \\
\text { Observa- } \\
\text { tions }\end{array}$ \\
\hline Corn & Spot & 0.000639 & 0.024595 & -0.239193 & 5.211582 & 234.2375 & 0.000000 & 1098 \\
& Futures & 0.000643 & 0.022415 & -0.020366 & 4.238126 & 70.20867 & 0.000000 & 1098 \\
Ethonol & & & & & & & & \\
& Spot1 & -0.000455 & 0.022932 & -1.764412 & 38.35293 & 57749.41 & 0.000000 & 1098 \\
& Spot2 & -0.000835 & 0.023590 & -1.59029 & 31.85003 & 38541.7 & 0.000000 & 1098 \\
& W. Europe & $-7.42 \mathrm{E}-05$ & 0.011947 & -0.93417 & 22.51938 & 17590.7 & 0.000000 & 1098 \\
& Futures & -0.000636 & 0.019722 & -1.22725 & 9.233364 & 2053.23 & 0.000000 & 1098 \\
Soy & & & & & & & & \\
& Spot & 0.000565 & 0.019156 & -0.663494 & 6.346485 & 592.9136 & 0.000000 & 1098 \\
& Futures & 0.000539 & 0.018640 & -0.693684 & 7.321802 & 942.5765 & 0.000000 & 1098 \\
Sugar & & & & & & & & \\
& Spot & 0.000494 & 0.021445 & -0.04355 & 4.252022 & 72.06279 & 0.000000 & 1098 \\
& Futures & 0.000296 & 0.024905 & -0.037579 & 5.334044 & 249.494 & 0.000000 & 1098 \\
\hline
\end{tabular}

Notes: Ethanol Spotlis the Chicago ethanol spot (ETHACHG), ethanol Spot 2 is the NYH ethanol Spot

(ETHANYH), Western European (Rotterdam) ethanol is ethanol spot (ETHEUT2), sugar Spot is raw sugar spot (SUGCNRW), sugar futures is sugar \# 11 futures traded at NBoT (NSBCS00), corn spot is corn spot \#2yellow (CORNUS2), corn futures is corn futures traded at CBOT (CSCS00),soybean spot is soybean spot\#1 yellow (SOYBEAN) and soybean futures is corn futures traded at CBOT(CSCS00). The numbers are first difference of logarithms or returns. The available common sample period for all the prices is June 23, 2006-Spetember 8, 2009. 
Table 2: Unit Root Tests Table 2: Unit Root Tests

\begin{tabular}{|c|c|c|c|c|c|c|}
\hline \multirow[t]{2}{*}{ Variables } & \multicolumn{3}{|l|}{ Level } & \multicolumn{3}{|l|}{ First difference } \\
\hline & ADF statistics & PP statistics & Lag & ADF statistics & PP statistics & Lag \\
\hline \multicolumn{7}{|l|}{ Spot } \\
\hline Corn & -2.519 & -2.539 & 4 & $-32.985^{* * *}$ & $-32.986^{* * *}$ & 3 \\
\hline Ethanol 1 & -2.979 & -2.985 & 12 & $-33.104^{* * *}$ & $-33.104^{* * *}$ & 11 \\
\hline Ethanol 2 & -4.695 & -4.688 & 4 & $-33.132^{* * *}$ & $-33.139^{* * *}$ & 3 \\
\hline Ethanol_Europe & -1.583 & -1.739 & 7 & $-32.483^{* * *}$ & $-32.601^{* * *}$ & 7 \\
\hline Soy & -1.960 & -1.978 & 12 & $-33.402^{* * *}$ & $-33.411^{* * *}$ & 11 \\
\hline Sugar & -0.337 & -0.298 & 15 & $-34.221^{* * *}$ & $-34.213^{* * *}$ & 15 \\
\hline
\end{tabular}

Futures

\begin{tabular}{lllllll} 
Corn & -2.398 & -2.430 & 4 & $-32.011^{* * *}$ & $-32.012^{* * *}$ & 3 \\
Ethanol & -3.868 & -3.872 & 11 & $-32.890^{* * *}$ & $-33.114^{* * *}$ & 9 \\
Soy & -1.999 & -2.008 & 2 & $-31.828^{* * *}$ & $-31.826^{* * *}$ & 4 \\
Sugar & -0.993 & -0.933 & 9 & $-33.473^{* * *}$ & $-33.509^{* * *}$ & 10 \\
\hline
\end{tabular}

Notes: $(* * *)$ shows significance at $1 \%$. The lengths of the lags provided in the table are pertinent to the PhillipsPerron (PP) test. For the ADF test, all the lags for the logged levels and the first differences are zero. The critical values are: -3.4608 for $1 \%$ significance, -2.8679 for $5 \%$, and -2.5681 for $10 \%$. See also the notes under Table 1 for definition of the notation. 
Table 3-A: Estimates of Bivariate MTAR Cointegration Models for Ethanol Spreads

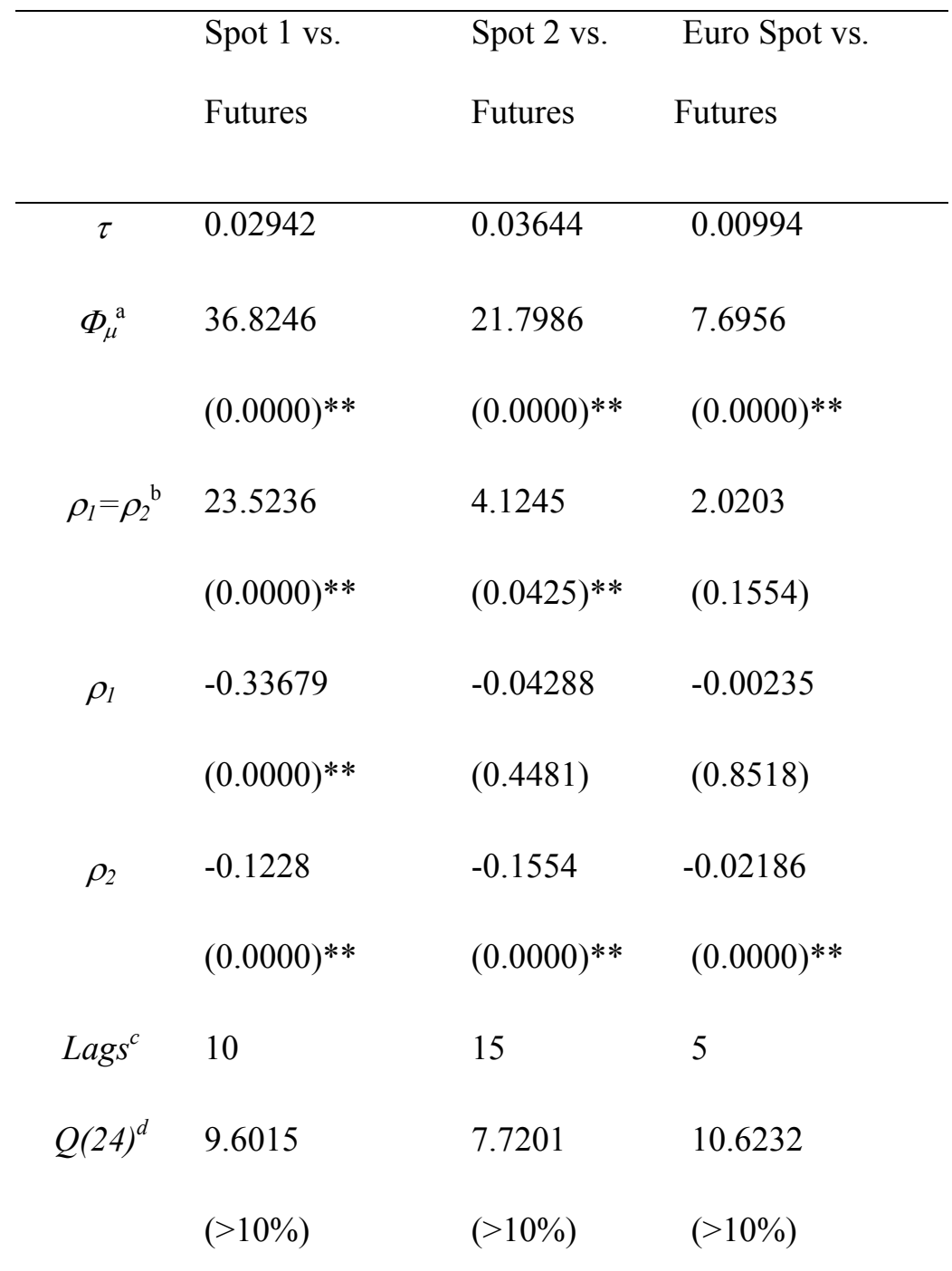

Notes: The spread $=$ spot - futures. Spot 1 is ethanol spot (ETHACHG) traded on Chicago Board of Trade, while Spot 2 is New York Harbor ethanol (ETHANYH).traded on New York Mercantile Exchange. Sample period is: $6 / 23 / 2006$ to $9 / 8 / 2010$. ${ }^{\text {a }}$ The $\Phi$ test is an F-test of the joint hypothesis $\rho_{1}=0$ and $\rho_{2}=0$ for each pair of spot and futures prices of the ethanol types. ${ }^{\mathrm{b}} \rho_{1}=\rho_{2}$ tests the null hypothesis that there is symmetric adjustment. The estimated $\rho_{l}$ and $\rho_{2}$ measure the speeds of the widening and narrowing adjustments, respectively. ${ }^{\mathrm{c}}$ The lag used for each test is determined using the general-to-specific method (Ng and Perron, 1995), with a maximum lag order of $24{ }^{\mathrm{d}} Q(24)$ is the Box-Pierce Q statistic for the first 24 autocorrelations of the residuals to be jointly zero. The pvalues corresponding to individual test statistics are given in parentheses. Statistical significance is indicated by double asterisks $(* *)$ at the $5 \%$ level. 


\section{Table 3-B}

Estimates of the Bivariate MTAR Cointegration Models for Sugar, Corn and Soybean Spreads

\begin{tabular}{|c|c|c|c|}
\hline & Sugar & Corn & Soybean \\
\hline & Spot vs. Futures & Spot vs.Futures & Spot vs. Futures \\
\hline$\tau$ & -0.0224 & -0.0187 & 0.0109 \\
\hline \multirow[t]{2}{*}{$\Phi_{\mu}{ }^{\mathrm{a}}$} & 13.4787 & 22.0728 & 21.3092 \\
\hline & $(0.0000)^{* *}$ & $(0.0000)^{* *}$ & $(0.0000)^{* *}$ \\
\hline \multirow[t]{2}{*}{$\rho_{1}=\rho_{2}^{\mathrm{b}}$} & 26.4848 & 31.0159 & 36.3105 \\
\hline & $(0.0000)^{* *}$ & $(0.0000)^{* *}$ & $(0.0000)^{* *}$ \\
\hline \multirow[t]{2}{*}{$\rho_{l}$} & 0.0035 & -0.0346 & 0.1861 \\
\hline & $(0.5866)$ & $(0.0082)^{* *}$ & $(0.0000)^{* *}$ \\
\hline \multirow[t]{2}{*}{$\rho_{2}$} & -0.1303 & -0.3077 & -0.0414 \\
\hline & $(0.0000)^{* *}$ & $(0.0000)^{* *}$ & $(0.0000)^{* *}$ \\
\hline $\operatorname{Lags}^{c}$ & 8 & 24 & 24 \\
\hline \multirow[t]{2}{*}{$Q(24)^{d}$} & 7.1235 & 1.7979 & 4.6088 \\
\hline & $(>10 \%)$ & $(>10 \%)$ & $(>10 \%)$ \\
\hline
\end{tabular}

Notes: See Table 3-A. 
Table 3-C

Estimates of the M-TAR Cointegration Hybrid Model

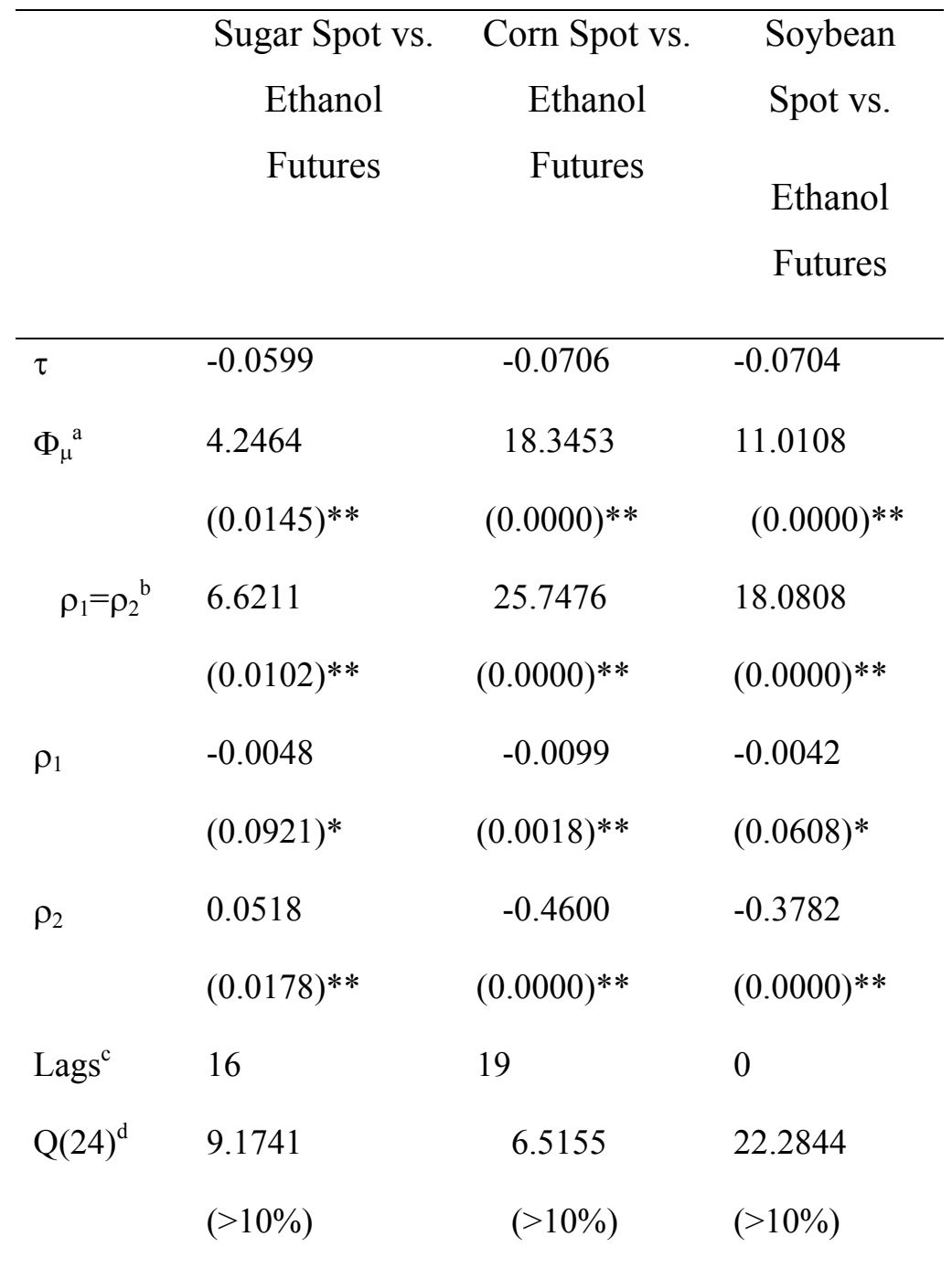

Notes: See Table 3-A. 
Table 4-A: MTAR-VEC Models for Ethanol Pairs of Spot and Futures Prices

\begin{tabular}{|c|c|c|c|c|}
\hline \multirow[b]{2}{*}{ Hypotheses } & \multicolumn{2}{|c|}{ Ethanol } & \multicolumn{2}{|c|}{ Ethanol } \\
\hline & $\Delta$ Spot 1 & $\Delta$ Futures & $\Delta$ Spot 2 & $\Delta$ Futures \\
\hline HO: Long term symmetry ${ }^{\mathrm{a}}$ & $\begin{array}{c}35.9019 \\
(0.0000)^{* *}\end{array}$ & $\begin{array}{c}0.8121 \\
(0.3677)\end{array}$ & $\begin{array}{c}1.6111 \\
(0.2046)\end{array}$ & $\begin{array}{c}8.4223 \\
(0.0037)^{* *}\end{array}$ \\
\hline $\begin{array}{l}\text { HO: Long term }+ \text { Short-term } \\
\text { symmetry }^{\mathrm{a}}\end{array}$ & $\begin{array}{c}2.2901 \\
(0.0000)^{* *}\end{array}$ & $\begin{array}{c}1.1434 \\
(0.2421)\end{array}$ & $\begin{array}{c}2.2028 \\
(0.0000)^{* *}\end{array}$ & $\begin{array}{c}1.3572 \\
(0.0607)^{*}\end{array}$ \\
\hline HO: Short-term symmetry ${ }^{\mathrm{a}}$ & $\begin{array}{c}1.6184 \\
(0.0072)^{* *}\end{array}$ & $\begin{array}{c}1.1689 \\
(0.2121)\end{array}$ & $\begin{array}{c}2.1983 \\
(0.0000)^{* *}\end{array}$ & $\begin{array}{c}1.3397 \\
(0.0709)^{*}\end{array}$ \\
\hline$\lambda^{+}$ & $\begin{array}{c}-0.4075 \\
(0.0000)^{* *}\end{array}$ & $\begin{array}{l}-0.0459 \\
(0.3223)\end{array}$ & $\begin{array}{l}-0.0926 \\
(0.1229)\end{array}$ & $\begin{array}{c}-0.1237 \\
(0.0285)^{* *}\end{array}$ \\
\hline$\lambda-$ & $\begin{array}{c}-0.1318 \\
(0.0000)^{* *}\end{array}$ & $\begin{array}{r}-0.0075 \\
(0.7603)\end{array}$ & $\begin{array}{c}-0.1619 \\
(0.0000)^{* *}\end{array}$ & $\begin{array}{c}0.0251 \\
(0.3395)\end{array}$ \\
\hline $\operatorname{Lags}^{b}$ & 22 & 22 & 22 & 22 \\
\hline$Q(24)^{c}$ & $\begin{array}{l}5.1702 \\
(>10 \%)\end{array}$ & $\begin{array}{l}6.2537 \\
(>10 \%)\end{array}$ & $\begin{array}{l}1.3400 \\
(>10 \%)\end{array}$ & $\begin{array}{l}3.8213 \\
(>10 \%)\end{array}$ \\
\hline
\end{tabular}

Notes: Spot 1 is ethanol spot (ETHACHG) traded on Chicago Board of Trade, while Spot 2 is New York Harbor ethanol (ETHANYH) traded on New York Mercantile Exchange. We do not include the Western European (Rotterdam) spot price in this table because there was no asymmetric cointegration. The sample period is $6 / 23 / 2006$ to $9 / 8 / 2010$. The null hypothesis for no long-term symmetry is no cointegration with MTAR adjustment $\left(\rho_{1}=\rho_{2}=0\right)$. The null hypothesis for the short term sets all the past changes in all prices jointly zero. ${ }^{\mathrm{a}}$ These are F-statistics with significance in parentheses. ${ }^{\mathrm{b}}$ The lag used for each test is determined using the general-to-specific method ( $\mathrm{Ng}$ and Perron, 1995), with a maximum lag order of $24{ }^{\circ}$ $Q(24)$ is the Box-Pierce $\mathrm{Q}$ statistic for the first 24 autocorrelations of the residuals to be jointly zero. The pvalues corresponding to individual test statistics are given in parentheses. Statistical significance is indicated by double asterisks $\left({ }^{* *}\right)$ at the $5 \%$ level and one asterisk $\left(^{*}\right)$ at the $10 \%$ level. $\lambda^{+}$represents the speed of adjustment of the individual price in the aftermath of a negative shock which causes a contango, while $\lambda$ - stands for the adjustment speed of the individual price in the aftermath of a positive shock that causes a backwardation. 
Table 4-B: MTAR-VEC Models for Price Pairs of Sugar, Corn and Soybean

\begin{tabular}{|c|c|c|c|c|}
\hline \multirow[b]{2}{*}{ Hypotheses } & \multicolumn{2}{|c|}{ Sugar } & \multicolumn{2}{|c|}{ Corn } \\
\hline & $\Delta$ Spot & $\Delta$ Futures & $\Delta$ Spot & $\Delta$ Futures \\
\hline HO: Long term symmetry ${ }^{\mathrm{a}}$ & $\begin{array}{c}2.4036 \\
(0.1213)\end{array}$ & $\begin{array}{c}3.4450 \\
(0.0637)^{*}\end{array}$ & $\begin{array}{c}1.7601 \\
(0.1849)\end{array}$ & $\begin{array}{c}0.1100 \\
(0.7402)\end{array}$ \\
\hline $\begin{array}{l}\text { HO: Long term + Short-term } \\
\text { symmetry }^{\mathrm{a}}\end{array}$ & $\begin{array}{c}1.4927 \\
(0.0227)^{* *}\end{array}$ & $\begin{array}{c}1.5231 \\
(0.0177)^{* *}\end{array}$ & $\begin{array}{c}0.9721 \\
(0.5257)\end{array}$ & $\begin{array}{c}0.9131 \\
(0.6366)\end{array}$ \\
\hline HO: Short-term symmetry ${ }^{\mathrm{a}}$ & $\begin{array}{c}1.4438 \\
(0.0350)^{* *}\end{array}$ & $\begin{array}{c}1.5048 \\
(0.0216)^{* *}\end{array}$ & $\begin{array}{c}0.9278 \\
(0.6073)\end{array}$ & $\begin{array}{c}0.9284 \\
(0.6064)\end{array}$ \\
\hline$\lambda^{+}$ & $\begin{array}{l}0.0156 \\
(0.1111)\end{array}$ & $\begin{array}{c}0.0071 \\
(0.5446)\end{array}$ & $\begin{array}{l}-0.0328 \\
(0.3481)\end{array}$ & $\begin{array}{c}0.0027 \\
(0.9307)\end{array}$ \\
\hline$\lambda-$ & $\begin{array}{l}-0.0431 \\
(0.2427)\end{array}$ & $\begin{array}{c}0.0922 \\
(0.0387)^{* *}\end{array}$ & $\begin{array}{l}-0.2453 \\
(0.1189)\end{array}$ & $\begin{array}{c}0.0510 \\
(0.7210)\end{array}$ \\
\hline $\operatorname{Lags}^{b}$ & 21 & 21 & 22 & 22 \\
\hline$Q(24)^{c}$ & $\begin{array}{l}2.0542 \\
(>10 \%)\end{array}$ & $\begin{array}{l}3.9015 \\
(>10 \%)\end{array}$ & $\begin{array}{l}7.6371 \\
(>10 \%)\end{array}$ & $\begin{array}{c}17.4549 \\
(>10 \%)\end{array}$ \\
\hline
\end{tabular}

Notes: See Table 4-A. 
Table 4-B: MTAR-VEC Models (Cont’d)

\begin{tabular}{|c|c|c|}
\hline \multirow[b]{2}{*}{ Hypothese } & \multicolumn{2}{|c|}{ Soybean } \\
\hline & $\Delta$ Spot & $\Delta$ Futures \\
\hline HO: Long term symmetry & $\begin{array}{c}0.0756 \\
(0.7832)\end{array}$ & $\begin{array}{c}0.8044 \\
(0.3699)\end{array}$ \\
\hline $\begin{array}{l}\text { HO: Long term }+ \text { Short-term } \\
\text { symmetry }\end{array}$ & $\begin{array}{c}1.8378 \\
(0.0006)^{* *}\end{array}$ & $\begin{array}{c}1.6233 \\
(0.0056)^{* *}\end{array}$ \\
\hline HO: Short-term symmetry & $\begin{array}{c}1.8718 \\
(0.0004)^{* *}\end{array}$ & $\begin{array}{c}1.5902 \\
(0.0084)^{* *}\end{array}$ \\
\hline$\lambda^{+}$ & $\begin{array}{l}-0.0312 \\
(0.8305)\end{array}$ & $\begin{array}{c}-1.090 \\
(0.4490)\end{array}$ \\
\hline$\lambda^{-}$ & $\begin{array}{c}0.0087 \\
(0.7898)\end{array}$ & $\begin{array}{c}0.0195 \\
(0.5451)\end{array}$ \\
\hline $\operatorname{Lags}^{b}$ & 23 & 23 \\
\hline$Q(24)^{c}$ & $\begin{array}{l}3.9773 \\
(>10 \%)\end{array}$ & $\begin{array}{l}10.9368 \\
(>10 \%)\end{array}$ \\
\hline
\end{tabular}

Note: See Table 4-A. 
Table 4-C: The MTAR-VEC Hybrid Models

\begin{tabular}{|c|c|c|c|c|}
\hline & $\begin{array}{c}\Delta \text { Sugar } \\
\text { Spot }\end{array}$ & $\begin{array}{c}\Delta \text { Ethanol } \\
\text { Futures }\end{array}$ & $\begin{array}{c}\Delta \text { Corn } \\
\text { Spot }\end{array}$ & $\begin{array}{r}\Delta \text { Ethanol } \\
\text { Futures }\end{array}$ \\
\hline HO: Long term symmetry ${ }^{a}$ & $\begin{array}{l}4.8371 \\
(0.0280)^{* *}\end{array}$ & $\begin{array}{l}0.7551 \\
(0.3850)\end{array}$ & $\begin{array}{l}16.2235 \\
(0.0000)^{* *}\end{array}$ & $\begin{array}{l}6.0517 \\
(0.0140)^{* *}\end{array}$ \\
\hline $\begin{array}{l}\text { HO: Long term }+ \text { Short-term } \\
\text { symmetry }^{\mathrm{a}}\end{array}$ & $\begin{array}{l}1.2529 \\
(0.1256)\end{array}$ & $\begin{array}{l}1.4077 \\
(0.0413)^{* *}\end{array}$ & $\begin{array}{l}2.2242 \\
(0.0000)^{* *}\end{array}$ & $\begin{array}{l}1.8986 \\
(0.0003)^{* *}\end{array}$ \\
\hline HO: Short-term symmetry ${ }^{\mathrm{a}}$ & $\begin{array}{l}1.1183 \\
(0.2783)\end{array}$ & $\begin{array}{l}1.4391 \\
(0.0335)^{* *}\end{array}$ & $\begin{array}{l}1.7963 \\
(0.0010)^{* *}\end{array}$ & $\begin{array}{l}1.9079 \\
(0.0003)^{* *}\end{array}$ \\
\hline$\lambda^{+}$ & $\begin{array}{l}-0.0029 \\
(0.2570)\end{array}$ & $\begin{array}{l}-0.0020 \\
(0.3640)\end{array}$ & $\begin{array}{l}-0.0073 \\
(0.0672)^{*}\end{array}$ & $\begin{array}{l}0.0050 \\
(0.1051)\end{array}$ \\
\hline$\lambda-$ & $\begin{array}{l}0.0436 \\
(0.0377)^{* *}\end{array}$ & $\begin{array}{l}0.0140 \\
(0.4441)\end{array}$ & $\begin{array}{l}-0.8919 \\
(0.0000)^{* *}\end{array}$ & $\begin{array}{l}-0.4127 \\
(0.0152)^{* *}\end{array}$ \\
\hline $\operatorname{Lags}^{b}$ & 22 & 22 & 23 & 23 \\
\hline$Q(24)^{c}$ & $\begin{array}{l}1.9122 \\
(>10 \%)\end{array}$ & $\begin{array}{l}10.3496 \\
(>10 \%)\end{array}$ & $\begin{array}{l}4.0648 \\
(>10 \%)\end{array}$ & $\begin{array}{l}14.8492 \\
(>10 \%)\end{array}$ \\
\hline
\end{tabular}

Notes: The bivariate VEC hybrid models are for cross pairs that each contains one spot return of the three grains and the ethanol futures return. Other notes are as in Table 4-A. 
Table 4-C: The MTAR-VEC Hybrid Models (continued)

\begin{tabular}{|c|c|c|}
\hline & $\begin{array}{c}\Delta \text { Soybean } \\
\text { Spot }\end{array}$ & $\begin{array}{r}\Delta \text { Ethanol } \\
\text { Futures }\end{array}$ \\
\hline HO: Long term symmetry & $\begin{array}{c}5.6467 \\
(0.0176)^{* *}\end{array}$ & $\begin{array}{c}0.8931 \\
(0.3448)\end{array}$ \\
\hline $\begin{array}{l}\text { HO: Long term }+ \text { Short-term } \\
\text { symmetry }\end{array}$ & $\begin{array}{c}2.4697 \\
(0.0000)^{* *}\end{array}$ & $\begin{array}{c}1.7411 \\
(0.0020)^{* *}\end{array}$ \\
\hline HO: Short-term symmetry & $\begin{array}{c}2.0927 \\
(0.0000)^{* *}\end{array}$ & $\begin{array}{c}1.6242 \\
(0.0068)^{* *}\end{array}$ \\
\hline$\lambda^{+}$ & $\begin{array}{c}-0.0052 \\
(0.0248)^{* *}\end{array}$ & $\begin{array}{c}0.0012 \\
(0.6010)\end{array}$ \\
\hline$\lambda^{-}$ & $\begin{array}{c}-0.4964 \\
(0.0164)^{* *}\end{array}$ & $\begin{array}{l}-0.1953 \\
(0.3479)\end{array}$ \\
\hline $\operatorname{Lags}^{b}$ & 22 & 22 \\
\hline$Q(24)^{c}$ & $\begin{array}{l}4.3718 \\
(>10 \%)\end{array}$ & $\begin{array}{l}16.2001 \\
(>10 \%)\end{array}$ \\
\hline
\end{tabular}

